\title{
Decreasing incidence of PID in Amsterdam
}

\author{
R A Coutinho, A J Rijsdijk, J A R van den Hoek, A Leentvaar-Kuijpers
}

\author{
Municipal Health \\ Service, Department \\ of Public Health and \\ Environment, \\ Amsterdam \\ R A Coutinho \\ J A R van den Hoek \\ A Leentvaar-Kuijpers \\ Address for correspondence: \\ R A Coutinho, Municipal \\ Health Service, PO Box \\ 20244, $1000 \mathrm{HE}$ \\ Amsterdam, The \\ Netherlands
}

\begin{abstract}
Objective-To study the incidence of pelvic inflammatory disease (PID) in Amsterdam in the period 1983-1990.

Methods-Patients diagnosed with PID based on a clinical definition were reported weekly by 30 general practices who covered $11 \%$ of the Amsterdam population. Annual age specific incidences were calculated using the number of women in the participating practices as the denominator.

Results-The PID incidence was approximately 50 per 10000 women through 1986, and then started to decrease in 1987 to reach 24 per 10000 in 1990. The decreasing trend since 1987 was seen in the age-groups $20-24,25-34$ and $35-44$ years, but not among teenagers. The moment of decline coincided with extensive attention given in the Dutch media to the risk of heterosexual transmission of the human immunodeficiency virus (HIV).
\end{abstract}

Conclusion-It is plausible that the declining incidence of PID was influenced by a change of heterosexual behaviour under the threat of AIDS.

(Genitourin Med 1992;68:353-355)

\section{Introduction}

Pelvic inflammatory disease (PID) is an ascending infection mostly caused by sexually transmitted micro-organisms, especially Chlamydia trachomatis (CT) and $N$ gonorrhoeae (NG). Evidence from a long term still ongoing follow-up study among women diagnosed by laparoscopy with PID-performed in Lund, Sweden-indicates that after one episode of PID $11 \%$ of the women became infertile, irrespective of treatment given. ${ }^{1}$ Because of these long term sequelae, PID is generally considered to be one of the most important complications of a sexually transmitted disease (STD) in women and it is a major public health problem with considerable economic consequences. $^{2}$

As PID is not reportable in most areas of the world, insight into the incidence of PID has been obtained through special surveys, hospital discharge rates for PID or extrapolations from the prevalence of STD's. ${ }^{3-5}$

The present prospective study of the PID incidence in Amsterdam was conducted in a group of general practices over the years 1983-1990, using a clinical definition. We were especially interested in the trend over the years to monitor possible variations that may be associated with a behavioural change among heterosexuals under the influence of the AIDS epidemic.

\section{Methods}

In 1978 all 380 general practitioners who practised at that time in the city of Amsterdam were invited to participate in a sentinel project with the purpose to monitor specific diseases and health related conditions in the city. ${ }^{6} \mathrm{~A}$ total of 141 general practitioners indicated that they were willing to participate and 30 of them were chosen on the basis of the location in the city and the size of their practice.

A census of their patient population revealed that the 30 general practices covered $11.4 \%$ of the Amsterdam population (approximately 700000 inhabitants). There was no difference in the age- and sex-distribution between the sample and the total population of the city.

Over the years four practices left the Amsterdam Sentinel Project (ASP) - mostly because the general practitioners stopped practisingand they were replaced by other general practices in the same area of the city.

The census of the patient population of the participating practices is repeated every 3-4 years and over the years the proportion of the Amsterdam population covered by the ASP remained around $11 \%$.

The general practices participating in the ASP weekly report certain diseases and health related conditions - that are defined according to strict criteria-by gender and age-group to the Department of Public Health of the Municipal Health Service of Amsterdam.

PID was reported in the years 1983-19907 using the following (clinical) definition: $a$ (female) patient with lower abdominal pain of acute onset; on physical examination the findings are: lower abdominal pressure tenderness, cervical motion tenderness and adnexal tenderness. Fever $\left(>38^{\circ} \mathrm{C}\right.$ rectal), leucocytosis and an elevated sedimentation rate support the diagnosis. The criterium for reporting the patient is whether antibiotics were prescribed either by yourself or by a gynaecologist.

Patients diagnosed with PID according to this definition who belonged to the patient population of the reporting practice were reported weekly on a standard form by agegroup. Annual incidences (by age-group) were calculated using the data about the patient population of the participating practices obtained through the most recent census. 


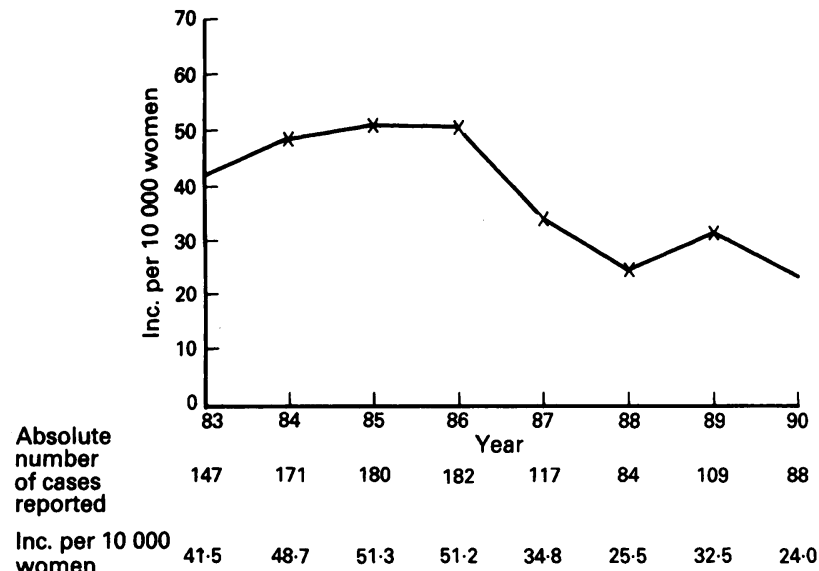

$\begin{array}{lllllllll}\text { Inc. per } 10000 & 41.5 & 48.7 & 51.3 & 51.2 & 34.8 & 25.5 & 32.5 & 24.0\end{array}$

Figure 1 Incidence of PID per year (per 10000 women).

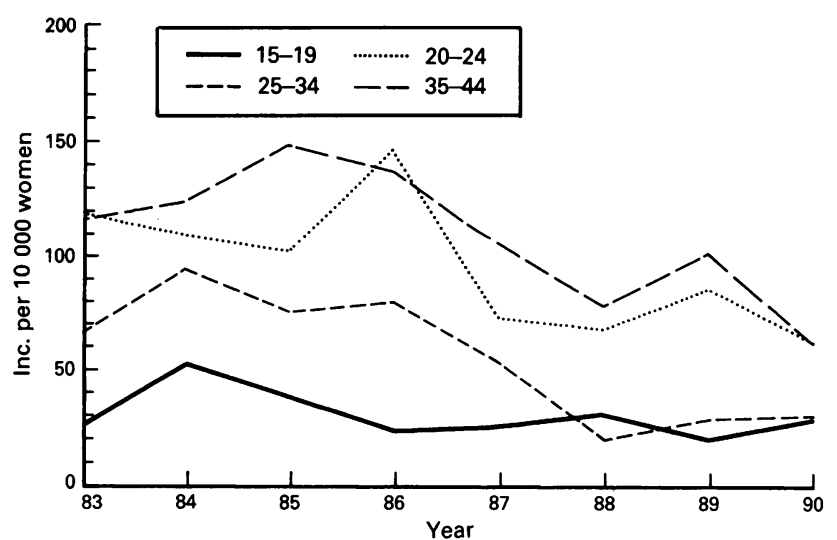

Figure 2 Incidence of PID by age group (per 10000 women).
The number of women (per age-group) in the participating practices was taken as the denominator. If practices were closed during certain periods, cq during holidays, the denominator was adjusted for this.

To test for changes in the incidence over the years, the chi square trend test was used and a $p$ value of 0.05 was chosen as criterium of significance.

\section{Results}

In 1983, the first year of registration, 147 cases of PID were reported by the 30 general practices participating in the Amsterdam sentinel project, the incidence per 10000 women being 41.5 in that year. In 1984 the incidence increased slightly to $48 \cdot 7$ per 10000 women and the annual incidence remained stable at approximately this level through 1986 (fig 1). However, in 1987 the incidence decreased to 34.8 and in 1988 a further decline occurred to 25.5. The incidence virtually remained at this level in 1989 and 1990. The decreasing trend in the incidence was significant $\left(\chi^{2}\right.$ for trend $47 \cdot 8, \mathrm{p}<0.0000)$.

Over the years the highest PID incidence was found alternately in the age-groups 20-24 and 25-34, ranging from 100 to 150 per 10000 women in these age-groups in

Table Absolute number of reported cases of PID and the incidence per 10000 for the age-groups 15-44 years in the Amsterdam sentinel project, 1983-1990

\begin{tabular}{|c|c|c|c|c|c|c|c|c|}
\hline & \multicolumn{8}{|c|}{ Age-group in years } \\
\hline & \multicolumn{2}{|c|}{$15-19^{*}$} & \multicolumn{2}{|c|}{$20-24 t$} & \multicolumn{2}{|c|}{$25-34 \ddagger$} & \multicolumn{2}{|c|}{$35-440$} \\
\hline & $a b s$ & inc & $a b s$ & inc & $a b s$ & inc & $a b s$ & inc \\
\hline $\begin{array}{l}1983 \\
1984 \\
1985 \\
1986 \\
1987 \\
1988 \\
1989 \\
1990\end{array}$ & $\begin{array}{r}6 \\
11 \\
8 \\
5 \\
5 \\
6 \\
4 \\
5\end{array}$ & $\begin{array}{l}26 \\
53 \\
38 \\
26 \\
25 \\
31 \\
20 \\
29\end{array}$ & $\begin{array}{l}38 \\
33 \\
31 \\
47 \\
23 \\
21 \\
27 \\
19\end{array}$ & $\begin{array}{r}119 \\
109 \\
102 \\
147 \\
73 \\
68 \\
86 \\
62\end{array}$ & $\begin{array}{l}71 \\
78 \\
94 \\
84 \\
62 \\
45 \\
59 \\
42\end{array}$ & $\begin{array}{r}116 \\
124 \\
149 \\
137 \\
106 \\
78 \\
101 \\
62\end{array}$ & $\begin{array}{r}25 \\
41 \\
33 \\
36 \\
24 \\
9 \\
13 \\
16\end{array}$ & $\begin{array}{l}66 \\
94 \\
75 \\
80 \\
54 \\
20 \\
29 \\
31\end{array}$ \\
\hline
\end{tabular}

1983-1986 and decreasing to 62 in both agegroups in 1990 (table). From 1987 onwards the incidence in the age-groups 20-24, 25-34 and 35-44 decreased significantly. In the agegroup 15-19, however, such a significant decrease was not seen (table and fig 2).

\section{Discussion}

In our study we observed a marked decline in the PID incidence in the city of Amsterdam in 1987, which stabilised in 1989 and 1990. A similar trend was seen in the absolute number of cases of PID diagnosed at our STD-clinics, which decreased from 118 and 123 in 1985 and 1986 to 96 in 1987, 66 in 1988 and 67 in 1989. In time this decline coincided with extensive attention that was given in the Dutch media to the risk of heterosexual transmission of the human immunodeficiency virus (HIV), the cause of AIDS. The media attention was fuelled by a government sponsored general informational campaign on AIDS which started in the Netherlands in April 1987.

The campaign was targetted towards the general public and stressed the necessity to practice safe sex for everyone with multiple sexual partners. The public awareness of AIDS resulting in a change of sexual behaviour among heterosexuals appears to be a most plausible explanation for the decreasing PID incidence in Amsterdam.

This explanation is reinforced by an earlier study in which we observed that the numbers of male and female heterosexual attenders of our two clinics for sexually transmitted diseases (STD) in Amsterdam also started to decline in $1987 .^{8}$

Recently Weström reported that the number of women discharged from hospital after being treated for PID decreased by $40 \%$ in Sweden between 1974 and $1984 .^{\circ}$ As this decrease mostly preceded the AIDS epidemic, his explanation for the decrease is a more conservative attitude towards sex among young people in Sweden, which is confirmed by sociological studies. It could be that such a change in sexual behaviour would have occurred in Amsterdam anyway, even without the AIDS epidemic. 
However, the concurrence in time is suggestive of a causal link. On the other hand the incidence of gonorrhoea in the Netherlands started to decline already in 1981 , well before a lot of media attention was given to AIDS. ${ }^{10}$ Apart from the direct influence that the declining gonorrhoea incidence has on the incidence of PID, this could also mean that a change of sexual behaviour among heterosexuals was occurring already before the AIDS epidemic and that the threat of AIDS just gave an extra impulse that accelerated this trend.

Our study of the trend of the PID incidence in Amsterdam over the years 1983-1990 among a very stable group of general practitioners is based on a clinical definition that did not change over the study period. Our surveillance definition probably overestimates the true PID incidence as there are no general accepted criteria fro the clinical diagnosis of PID and studies have shown that $20-30 \%$ of the clinical PID cases cannot be confirmed by laparoscopy. ${ }^{1112}$ On the other hand there is increasing evidence that PID can be clinically (nearly) asymptomatic, which leads to an underestimation of the true PID incidence. Another reason that our estimation is on the low side is that the participating general practitioners may not have been notified by the treating specialists about all cases of PID diagnosed among women who belong to their patient population.

In conclusion, the incidence of PID in Amsterdam has declined since 1987, most likely influenced by a change of heterosexual behaviour under the threat of AIDS. As both the number of AIDS cases and the HIV prevalence among heterosexuals in the Netherlands is presently (still) very low, it remains to be seen whether this change of behaviour is stable or whether a rebound effect will occur.

We thank the participating general practitioners of the Amsterdam Sentinel Project for their careful reporting and Erik van Ameijden for statistical advice.

1 Weström L, Mardh PA. Acute pelvic inflammatory disease. In: Sexually Transmitted Disease, Holmes KK, Mardh PA, Sparling PF, Wiesner PJ, Cates W, Lemon SM and Stamm WE ed. 2nd ed. New York. MGraw-Hill 1990.

2 Curran JW. Economic consequences of pelvic inflammatory disease in the United States. Am F Obstet Gynecol 1980; 138:848-51.

3 Adler MW. trends for gonorrhea and pelvic inflammatory disease in England and Wales and for gonorrhoea in a defined population. Am $\mathcal{f}$ Obstet Gynecol 1980;138: defined

4 Weström L. Incidence, prevalence and trends of acute pelvic inflammatory disease and its consequences in indusinflammatory disease and its consequences in indus-
trialized countries. Am $f$ Obstet Gynecol 1980;138: trialized

5 faarverslag 1979 Amsterdams Peilstation Projekt. GG en GD Amsterdam 1980

6 faarverslagen Amsterdams Peilstation Projekt 1983-1990. GG en GD Amsterdam 1984-1991.

7 Van Haastrecht HJA, Van den Hoek JAR, Coutinho RA. evidence for a change of behaviour among heterosexuals in Amsterdam under the influence of AIDS. Genitourin Med 1991;67:199-206.

8 Weström L. Decrease in incidence of women treated in hospitals for acute salpingitis in Sweden. Genitourin Med 1988;64:59-63.

9 Van de Laar MJW, Van den Hoek JAR, Pickering J, Van Griensven GJP, Coutinho RA, Van de Water HPA. Dalende trend van gonorroe in Nederland; betekenis voor de AIDS-epidemie? Ned Tijdschr Geneeskd 1990; 134:647-52.

10 Sweet RL. Diagnosis and treatment of pelvic inflammatory disease in the emergency room. Sexually Transmitted Diseases 1981;8:156-63.

11 faarverslagen Geslachtsziektenbestrijding GG en GD Amsterdam 1984-1990. GG en GD Amsterdam 1985-1991. 